\title{
Patient involvement in medication safety in hospital: an exploratory study
}

\author{
Soomal Mohsin-Shaikh • Sara Garfield • \\ Bryony Dean Franklin
}

Received: 27 July 2013/ Accepted: 9 April 2014/Published online: 29 April 2014

(C) The Author(s) 2014. This article is published with open access at Springerlink.com

\begin{abstract}
Background Medication errors are common in hospital inpatients. While many interventions have been proposed to address these problems, few have been shown to have significant benefits. A complementary approach is to facilitate greater involvement of patients with their inpatient medication. However, there is relatively little research in this area and it is not known which interventions lead to improved healthcare outcomes. Work is therefore needed to investigate the roles that healthcare professionals and patients believe are appropriate for hospital inpatients to take relating to safety. Objective To explore the extent to which hospital inpatients reported that they engaged with medication safety-related behaviours, the extent to which they would like to, and the extent to which healthcare professionals reported that they would support such engagement. Setting An NHS hospital Trust in West London. Methods 100 Patients and healthcare professionals were recruited on ten wards within the Trust and invited to complete quantitative questionnaires. Data were analysed descriptively and exploratory comparisons
\end{abstract}

Electronic supplementary material The online version of this article (doi:10.1007/s11096-014-9951-8) contains supplementary material, which is available to authorized users.

S. Mohsin-Shaikh · S. Garfield $(\bowtie) \cdot$ B. D. Franklin

The Centre for Medication Safety and Service Quality, Imperial College Healthcare NHS Trust, Charing Cross Hospital, Fulham Palace Road, London W6 8RF, UK

e-mail: sara.garfield@imperial.nhs.uk

S. Mohsin-Shaikh · S. Garfield · B. D. Franklin UCL School of Pharmacy, 29-39 Brunswick Square, London WC1N 1AX, UK made between different groups of respondents. Main outcome measures inpatient medication safety involvement scale and control preference scale for patient involvement in decision making. Results 100 patients (98\% response rate) and 104 healthcare professionals (59\% response rate) were recruited. The majority of patients and healthcare professionals were supportive of hospital inpatients being involved with their medication. However there was a significant gap between desire for patient involvement and what patients reported having experienced. Female patients and those under 65 wanted a significantly higher level of involvement than males and over $65 \mathrm{~s}$. Few associations were found between healthcare professionals' reported support for involvement and their profession or gender. However, pharmacists and nurses were significantly more likely to report supporting patients asking questions about their medicines and self administering their own medicines than doctors. Conclusion Healthcare professionals and patients desire a higher level of patient involvement with their medication while in hospital than patients currently report. Interventions need to be developed to bridge the gap between desired and actual patient involvement.

Keywords Hospital · Medication safety - Patient participation · Shared decision making · United Kingdom

\section{Impact of findings on practice}

- The gap between patients' preferred and experienced involvement with inpatient medication needs to be addressed.

- Healthcare professionals would support patients in being involved with their medication while in hospital, but they need to find ways to encourage this in practice. 


\section{Introduction}

The UK, USA and the World Health Organization [1-4] have identified that priority should be given to improved patient safety in healthcare. Medication error has been shown to be one of the most frequent forms of medical error and is associated with significant harm [5]. Medication errors are common in hospital inpatients. UK research suggests that prescribing errors occur in up to $15 \%$ of inpatient medication orders, commonly involving omission of patients' usual medication on admission, and $9 \%$ of medications prescribed at discharge [6]. A recent metaanalysis reports medication administration errors in $5.6 \%$ of non-intravenous doses and $35 \%$ of intravenous doses administered in the UK [7]. Although many of these do not result in patient harm, others have more serious consequences [8], and even errors which do not cause harm can seriously affect the patient's confidence in their healthcare.

While many interventions have been proposed to address these problems, few have been shown to have significant benefits [9]. A complementary approach, not yet widely studied, is to facilitate greater involvement of patients with their inpatient medication. In particular, patients (and their carers) are likely to know a great deal about medication that they have been using prior to admission. Patients are therefore a potentially important (and often the final) defence against errors relating to their medication.

Patient safety activities relating to inpatient medication include, but are not limited to, patients viewing their inpatient medication records, prompting staff to avoid dose omissions, providing information to aid handover between shifts and professional groups, and raising queries with prescribers, pharmacists or nursing staff. For example, in one Swiss study, oncology patients detected errors such as dose omissions [10]. Locally, observation of medication administration rounds has confirmed that patients do query their medication with ward staff, and sometimes prevent potential medication errors [11]. However, our experience also suggests that patients are often unsure of the medication they are prescribed as an inpatient, preventing effective engagement with their treatment and thus a more active role in medication safety. In particular, we have observed considerable confusion among both patients and hospital staff regarding whether or not hospital inpatients are 'permitted' to look at their hospital medication records where their current medication is prescribed and recorded.

Research has shown that patients are more willing to participate in patient safety if encouraged to do so by healthcare professionals [12-14]. However, there is relatively little research in this area. A patient partnership intervention has not shown a significant difference in adverse drug effects between intervention and control groups [15] and it is not known which interventions lead to improved healthcare outcomes [16]. Further work is therefore needed to investigate the roles that healthcare professionals and patients believe are appropriate for hospital inpatients to take relating to safety [17].

Aims of the study

In this paper we report the findings of a service evaluation which aimed to explore the extent to which hospital inpatients reported that they engaged with medication safetyrelated behaviours, the extent to which they stated they would like to, and the extent to which healthcare professionals reported that they would support such engagement.

\section{Objectives}

- To explore patients' views on being involved in different aspects of their medication while in hospital.

- To explore healthcare professionals' views on patients being involved in different aspects of their medication while in hospital.

- To explore whether views on patient involvement might differ between different healthcare professions, age groups and gender.

- To explore whether desired and reported patient involvement differ among patient genders and age groups.

- To identify any mismatches concerning views on involvement between patients and healthcare professionals.

- To identify any mismatches between the involvement patients would like and their experienced involvement.

\section{Methods}

This exploratory survey was exempt from ethical review and was approved as a service evaluation by the Quality and Safety Committee of the study Trust.

\section{Setting}

The study took place in three hospitals of an NHS Trust in West London in April and May 2013. There were a total of 82 wards in the Trust, each typically comprising about 20-25 beds. The Trust operated typical UK systems for prescribing, dispensing and administration of medication. Prescribing was paper-based, using pre-formatted drugcharts on which nurses also recorded medication administration. Commonly used medication was kept as ward stock with other medication dispensed for individual patients. 
Patients were also encouraged to bring their own medication into hospital. Procedures were in place to allow patients to self-administer medication where appropriate. Pharmacists visited each ward on weekdays to check that medication orders were clear, legal and clinically appropriate for each patient and to initiate the supply of any medication needed.

\section{Participants}

We excluded wards thought likely to have a very high proportion of unwell patients, as well as private wards. Convenience sampling [18] was then used to recruit ten wards from those remaining and then to identify patients and healthcare professionals on the participating wards. We studied a wide range of wards: gastroenterology, infectious diseases, medical admissions, gastrointestinal surgery and urology, trauma and orthopedics, elderly care rheumatology and endocrine, urogynaecology, post-natal and two stroke wards.

Healthcare professionals on participating wards assisted with the identification of patients likely to meet our inclusion criteria. Patients not speaking English, patients judged by the healthcare professionals to be too unwell or too cognitively impaired to participate and patients under 18 were excluded. The researcher (SMS) then approached potentially suitable patients, provided them with a verbal explanation of the study and offered a patient information leaflet. Patients were able to take as much time as they required to make a decision on whether to participate. Completion of the questionnaire was taken as consent.

When visiting a ward, the researcher (SMS) approached healthcare professionals on the ward at that time. All ward pharmacists within the Trust were approached by email. Respondents were given a brief explanation about the study and offered further written information if required. Completion of the questionnaire was taken as consent.

The target sample size was 100 patients and 100 healthcare professionals to allow for exploratory comparisons between different genders, age groups and healthcare professions.

\section{Instruments}

We used separate quantitative Questionnaires for healthcare professionals and patients (available online as supplementary material). These both comprised two scales; the first was developed for the present study, referred to as the inpatient medication safety involvement scale (IMSIS). The patient version comprised eight exploratory questions about views on patient participation in their medication in general while in hospital and medication safety in particular. The healthcare professional version had five questions as we asked for their views only, and not their experiences. We developed the IMSIS scale with reference to the literature [19-21] and in line with our research objectives. The second was the three item control preference scale [22], a validated instrument for measuring preferences for involvement in healthcare decision making, as adapted by Garfield et al. [23] to apply specifically to medication. The questionnaire also included questions on gender, age, and (for healthcare professionals) profession. The researcher piloted the questionnaire on the participating wards with nine healthcare professionals and five patients, and assessed responses for face and content validity and acceptability. Following piloting, a question on whether or not pharmacists were qualified independent prescribers was amended very slightly to make it clearer. As no other amendments were made, the pilot Questionnaires completed were included in the main study.

\section{Data collection}

The patients and healthcare professionals were presented with the questionnaire on the ward by the researcher who then collected the completed questionnaires. Respondents were able to take as much time as they wanted to complete the questionnaire. If a patient was unable to complete the questionnaire themselves, the researcher offered to read the questionnaire and complete it on their behalf. Questionnaires were also emailed to all the pharmacists working at the Trust and emailed back to the researcher; one reminder was sent 11 days later.

\section{Data entry and analysis}

Data were entered onto an SPSS (version 21) database which was then cleaned. Descriptive quantitative data were generated for all variables. We used Kreskas Wallis and Mann-Whitney $U$ tests to investigate whether there were significant differences between the views of different groups of healthcare professionals and between different genders and age groups of patients and healthcare professionals. Wilcoxon tests were used to test whether there were significant differences between patients' preferred involvement and the involvement they experienced. We used Cronbach's alpha to determine the internal reliability of both our new instrument on participation in medication safety (IMSIS) and the control preference scale [22, 23]. This provided information about whether or not it would be appropriate to combine the individual items into a scale and use summed scores for each of the two scales in further analysis. We calculated Cronbach's alpha separately for patients and healthcare professionals' data but did not subdivide healthcare professionals by profession as the numbers would have been too small for meaningful analysis. 
Where appropriate, we used Spearman's bivariate correlation to determine the strength of association between the two scales.

While this was primarily a quantitative study, any comments spontaneously added by respondents to the questionnaire or stated verbally to the researcher that informed the research objectives were recorded and analysed descriptively.

\section{Results}

\section{Response rates}

One hundred patients (98\% response rate), 24 doctors (80\% response rate), 30 pharmacists ( $31 \%$ response rate) and 50 nurses (100\% response rate) took part. Demographic data for both patients and healthcare professionals are presented in Table 1. The doctors who did not participate reported that they were too busy. One patient who did not participate reported that $\mathrm{s} / \mathrm{he}$ was too tired and the other that $\mathrm{s} / \mathrm{he}$ did not want to be involved with the study.

Patients' and healthcare professionals' views on inpatient involvement with medication, medication safety and prescribing decisions

The majority of patients and healthcare professionals were supportive of hospital inpatients being involved with their medication. Table 2 shows the level of involvement that patients both wished to have and actually reported having with different aspects of their medication, according to the IMSIS scale. Wilcoxon tests demonstrated a significant difference between the level of desired and experienced involvement, with patients wanting more involvement than they had actually experienced (Table 3). Table 4 shows the level of support

Table 1 Respondent characteristics

\begin{tabular}{lcl}
\hline Total sample size & $\begin{array}{l}\text { Patients } \\
100\end{array}$ & $\begin{array}{l}\text { Healthcare Professionals } \\
104\end{array}$ \\
\hline Gender & & \\
Male & 34 & 28 \\
Female & 66 & 76 \\
Age $\left(\mathrm{n}=99^{\mathrm{a}}\right)$ & & \\
$\leq 65$ & 56 & - \\
$>65$ & 44 & - \\
Type of Healthcare Professional & \\
Doctor & - & 24 \\
Pharmacist & - & 30 \\
Nurse & - & 50 \\
\hline
\end{tabular}

${ }^{a}$ Age was missing for one patient

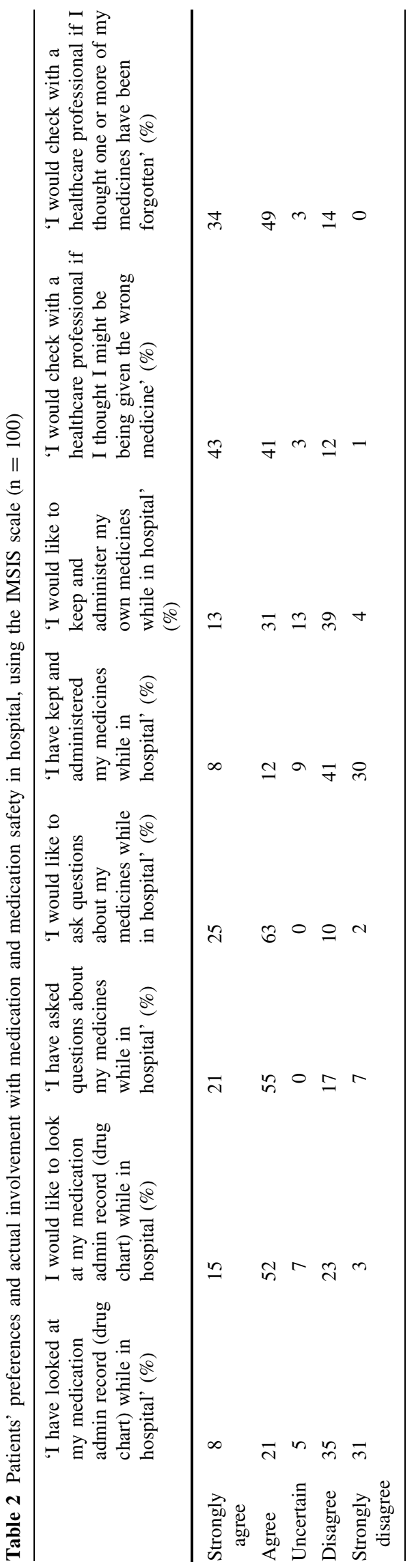


Table 3 Differences between desired and experienced patient involvement in different aspects of medication safety while in hospital, according to the IMSIS scale

\begin{tabular}{lll}
\hline Statements & Test & Significance \\
\hline $\begin{array}{c}\text { I have looked at my drug chart } \\
\text { while in hospital versus I }\end{array}$ & $\begin{array}{c}\text { Related samples- } \\
\text { Wilcoxon Signed }\end{array}$ & $p<0.001$ \\
would like to look at my drug & Rank Test & \\
chart while in hospital & \\
I have asked questions about & \\
my medicines while in & \\
hospital versus I would like & \\
to ask questions about my & \\
medicines while in hospital & \\
I have kept and administered & \\
my medicines while in & \\
hospital versus I would like & \\
to keep and administer my & \\
own medicines while in & \\
hospital &
\end{tabular}

Items measuring desired involvement without a matching item for experienced involvement not included

that healthcare professionals reported that they would have for patient involvement. Descriptive exploration of the results for each individual item in IMSIS suggests a trend towards healthcare professionals being more likely to say that they would support patient involvement than patients wanting such involvement. This is illustrated further in Fig. 1.

Table 5 and Fig. 2 shows patients' and healthcare professionals' preferences regarding who should make decisions about their medication, according to the control preference scale. Once again, there appeared to be a trend towards healthcare professionals reporting a preference for greater patient involvement in decision making than patients had themselves.

\section{Internal reliability of instruments used}

For both scales (IMSIS and the control preference scale), patients' data showed good internal consistency (Cronbach's alpha $>0.7$ ) suggesting it was appropriate to sum the individual items within the scale concerned to give overall scores for each scale for the remaining analysis (Table 6). However, the healthcare professionals' data did not show the same level of internal consistency for either scale (Cronbach's alpha $<0.7$ ); therefore in the remainder of the analysis, we consider healthcare professionals' responses to each individual item rather than considering an overall score for each scale.

Association between preference for general involvement with inpatient medication and involvement in decision making

For patients, there was a weak correlation between IMSIS scores and those for the control preference scale

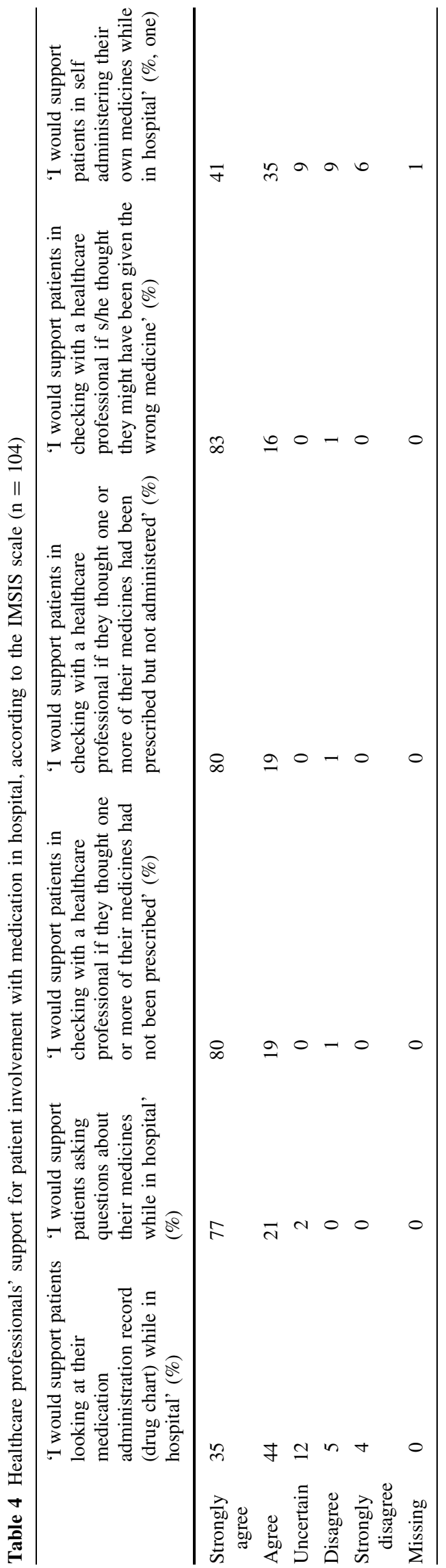


Fig. 1 Preferences for inpatient involvement with medication according to the IMSIS scale. HCPs: health care professionals

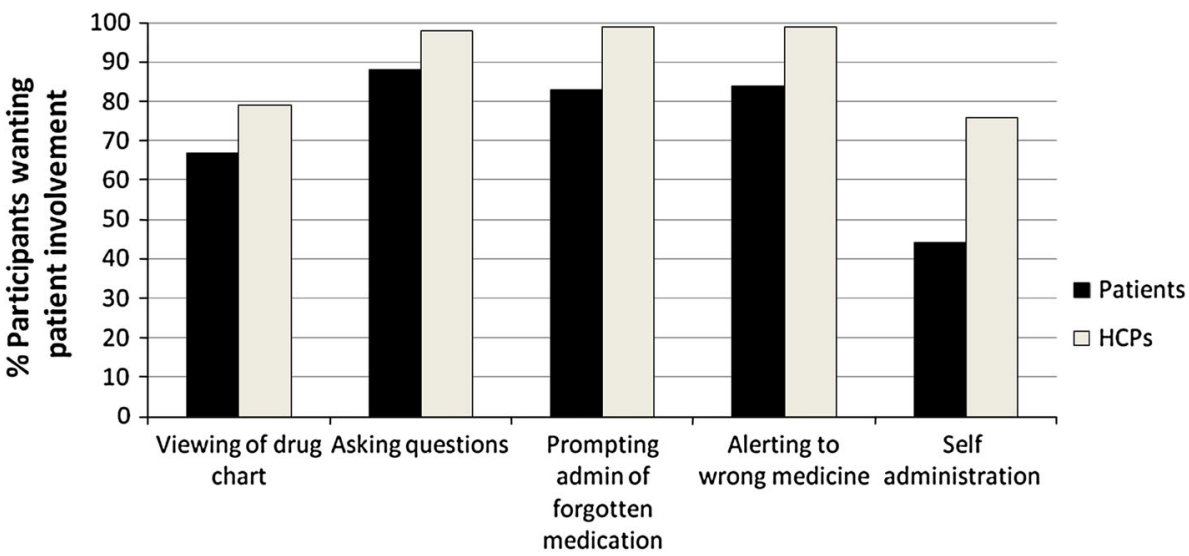

Medication related behaviours

Table 5 Patients' and healthcare professionals' preferences for involvement in decisions regarding their medication (adapted Control Preference Scale)

\begin{tabular}{|c|c|c|c|c|c|}
\hline \multicolumn{2}{|c|}{ Starting a new medicine } & \multicolumn{2}{|c|}{$\begin{array}{l}\text { Changing the dose of a } \\
\text { medicine that the patient } \\
\text { is already taking }\end{array}$} & \multicolumn{2}{|c|}{ Stopping a medicine } \\
\hline $\begin{array}{l}\text { Patient } \\
(\mathrm{n}=100)\end{array}$ & $\begin{array}{l}\text { Healthcare } \\
\text { professionals } \\
(\mathrm{n}=104)\end{array}$ & $\begin{array}{l}\text { Patient } \\
(\mathrm{n}=100)\end{array}$ & $\begin{array}{l}\text { Healthcare } \\
\text { professionals } \\
(\mathrm{n}=104)\end{array}$ & $\begin{array}{l}\text { Patient } \\
(\mathrm{n}=100)\end{array}$ & $\begin{array}{l}\text { Healthcare } \\
\text { professionals } \\
(\mathrm{n}=104)\end{array}$ \\
\hline 3 & 9 & 2 & 7 & 2 & 6 \\
\hline 8 & 30 & 11 & 16 & 10 & 13 \\
\hline 47 & 50 & 45 & 52 & 46 & 45 \\
\hline 24 & 9 & 26 & 20 & 30 & 27 \\
\hline 18 & 2 & 16 & 5 & 12 & 9 \\
\hline 100 & 100 & 100 & 100 & 100 & 100 \\
\hline
\end{tabular}

Fig. 2 Preferences for decision making when starting a new medicine using the adapted control preference scale. HCPs: health care professionals

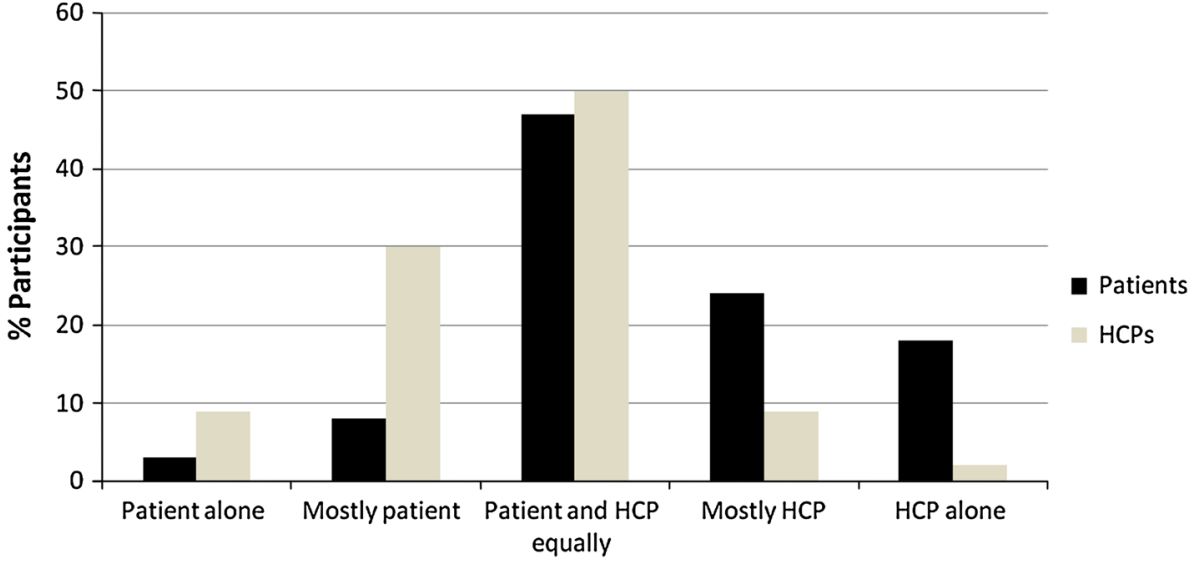

Preferences for decision making when starting a new medicine 
Table 6 Internal reliability of instruments used

\begin{tabular}{lll}
\hline Scale & Patients & $\begin{array}{l}\text { Healthcare } \\
\text { professionals }\end{array}$ \\
\hline Cronbach's Alpha & & \\
IMSIS & 0.733 & 0.574 \\
Adapted control preference scale & 0.857 & 0.665 \\
\hline
\end{tabular}

Table 7 Comparisons between gender and age groups for patients' IMSIS scale (Mann-Whitney U tests)

\begin{tabular}{llll}
\hline Total sample $(\mathrm{n}=100)$ & $\begin{array}{l}\text { Mean } \\
20.89\end{array}$ & $\begin{array}{l}\text { Standard deviation } \\
5.308\end{array}$ & $p$ value* \\
\hline Gender & & & \\
$\quad$ Male $(\mathrm{n}=34)$ & 23.21 & 4.663 & 0.003 \\
$\quad$ Female $(\mathrm{n}=66)$ & 19.70 & 5.256 & \\
Age & & & 0.002 \\
$\quad \leq 65(\mathrm{n}=56)$ & 19.52 & 5.350 & \\
$65<(\mathrm{n}=43)$ & 22.84 & 4.629 &
\end{tabular}

* Asymptotic significance values are displayed. The significance level is 0.05

The lower the score, the greater the involvement

Table 8 Comparisons between gender and age groups for patients' responses to the adapted Control Preference Scale (Mann-Whitney U tests)

\begin{tabular}{lrll}
\hline Total sample $(\mathrm{n}=100)$ & $\begin{array}{l}\text { Mean } \\
10.29\end{array}$ & $\begin{array}{l}\text { Standard deviation } \\
2.500\end{array}$ & $p$ value* \\
\hline Overall score for involvement with & decisions & \\
Gender & & & \\
Male $(\mathrm{n}=34)$ & 11.44 & 2.048 & $<0.001$ \\
Female $(\mathrm{n}=66)$ & 9.70 & 2.517 & \\
Age & & & $<0.001$ \\
$\leq 65(\mathrm{n}=56)$ & 9.50 & 2.296 & \\
$65<(\mathrm{n}=43)$ & 11.33 & 2.427 & \\
\hline
\end{tabular}

(Spearman's correlation coefficient $=0.41, p<0.001$ ). It was not appropriate to carry out this correlation test for healthcare professionals as Cronbach's alpha suggested internal reliability for each scale to be low.

Associations between patient involvement and age/ gender

Mann-Whitney $\mathrm{U}$ tests demonstrated that female patients $(p=0.003)$ and patients 65 and under $(p=0.002)$ had significantly higher scores for overall desired and experienced involvement with their medication in hospital than males and those over 65 respectively (Table 7). Females $(p<0.001)$ and those 65 and under $(p<0.001)$ were also more likely to want to be involved in decision making regarding medicines (Table 8).

Associations between healthcare professional support for patient involvement and gender/healthcare professional type

When individual items were tested, there were few associations between healthcare professional support for patient involvement with gender or healthcare professional type. However, Kruskal-Wallis (Table 9) and Mann-Whitney U tests showed that both pharmacists and nurses were significantly more likely to report that they would support patients asking questions about their medicines and self administering their own medicines than doctors $(p<0.001)$.

Barriers to patient involvement

Comments spontaneously added by respondents to the questionnaire or stated verbally to the researcher provided preliminary data regarding some of the barriers to patients being more involved with their medicines.

When patients were asked (1) if they would check with a healthcare professional if they thought one or more of their medicines may have been forgotten or (2) they might be being given the wrong medicine, two expressed the opinion that they trusted the healthcare professionals' expertise and would not challenge them.

One patient reported that patients' medicines may be changed or stopped while in hospital and that they may not have enough knowledge to self-administer their own medicines.

Three healthcare professionals cited patients' lack of cognitive ability and one cited patients' limited English as barriers to patient involvement. One nurse expressed the view that he did not have enough information about self administration of medicines to say whether or not he would support this. Some doctors reported that they would not like to be personally involved with self administration as they had other demands on their time; they would prefer nurses to take the lead on this.

\section{Discussion}

Both patients and healthcare professionals reported that they supported patient involvement in medication and medication safety. This supports the findings of Davis et al. $[12,17]$ when exploring patients' and healthcare professionals' views on patients general involvement in healthcare and safety and those of Schwappach and Wernli [14] 
Table 9 Comparisons among healthcare professional groups in terms of their support for patients asking questions about their medicines and self-administering (Kruskal-Wallis tests)

\begin{tabular}{|c|c|c|c|c|c|}
\hline Statement & Mean ranks & & $\begin{array}{l}\text { Chi square } \\
\text { statistic }\end{array}$ & $\begin{array}{l}\text { Degrees } \\
\text { of freedom }\end{array}$ & $p$ value \\
\hline \multirow{3}{*}{$\begin{array}{l}\text { I would support patients asking questions } \\
\text { about their medicines while in hospital' }\end{array}$} & Doctor & 69.13 & \multirow[t]{3}{*}{20.479} & \multirow[t]{3}{*}{2} & \multirow[t]{3}{*}{$<0.001$} \\
\hline & Pharmacist & 42.20 & & & \\
\hline & Nurse & 50.70 & & & \\
\hline \multirow{3}{*}{$\begin{array}{l}\text { 'I would support patients in self administering } \\
\text { their own medicines while in hospital' }\end{array}$} & Doctor & 70.98 & \multirow[t]{3}{*}{16.264} & \multirow[t]{3}{*}{2} & \multirow[t]{3}{*}{$<0.001$} \\
\hline & Pharmacist & 40.45 & & & \\
\hline & Nurse & 49.78 & & & \\
\hline
\end{tabular}

when investigating chemotherapy patients' engagement in medical error prevention. However, Davis et al. [12] found that patients reported lower willingness to notify doctors of problems or errors than to ask factual questions, but a higher willingness to notify nurses of errors than to ask factual questions. Other studies have shown that patients are more willing to participate in behaviours that were less challenging $[14,24]$. In our study, a similar proportion of patients wanted to ask questions about their medicines as said they would challenge a healthcare professional if they thought an error was being made. The reason for the difference in findings may be due to the fact that our study asked about healthcare professionals in general, rather than asking separately about doctors, nurses and pharmacists.

Female patients and those 65 and under wanted significantly more involvement in medication and medication safety than males and those over 65 . Findings from previous studies regarding the association between age and gender and preferences for involvement in healthcare safety have been inconclusive [21]. However, the finding that younger patients have higher preference for involvement in decisions about medicines is consistent with other research $[23,25]$. Previous research has also shown that younger patients are more likely to have a preference towards self administration of medicines in hospital [23]. Previous findings concerning gender and preference for involvement in decision making have been mixed [23, 25]. However, all studies that have identified an association with gender have concluded that women are the more likely to prefer a more active role [25]. In addition, female patients have been shown to be more likely to show a preference towards self administration of medication in hospitals [26].

Few associations were found between healthcare professional type and gender, and their preference for involvement. However, pharmacists and nurses were significantly more likely to support patients asking questions and self administering their medicines than doctors. Davis et al. [17] found that nurses were more likely to support patient involvement in safety than doctors.
There was a descriptive trend towards healthcare professionals reporting being more supportive of patient involvement with medication than patients in the individual items of both the IMSIS and control preference scales. Davis et al. [17] found that doctors were more likely to support patient involvement in safety as healthcare professionals than they would involve themselves as patients, although this effect was not observed for nurses.

Healthcare professionals showed less variation than patients in which specific patient involvement behaviours they strongly supported (Tables 2,4 ). Whilst both the IMISS and control preference scale had good internal reliability for patients, neither scale showed good internal reliability for healthcare professionals, suggesting that healthcare professionals' beliefs may not form one scale. This is the first study we are aware of where the control preference scale had been used for healthcare professionals. The results suggest that it may not be appropriate to group the items as one scale in analysis.

\section{Strengths and limitations}

Our study reported important exploratory findings regarding patients' and healthcare professionals' views on patient involvement in medication safety while in hospital. Unlike many studies in this field we included pharmacists as well as doctors and nurses. Limitations included that it was carried out in one trust and convenience sampling was used. However, patients were recruited from a variety of ward types and the response rates were mostly very high. The response rate for pharmacists was lower as fewer were present on the wards at the time of our researcher's visits and they therefore generally had to be recruited via email rather than in person. However, they were not likely to have represented a dramatically different range of specialties to healthcare professionals recruited on the wards because most pharmacists in the Trust each provide services to a wide range of wards. For the same reason, we do not have data on the total number of nurses and doctors working on the study wards and are therefore unable to 
calculate the proportion of these who completed our questionnaire. The views of patients who were too unwell to participate or did not speak English were not represented. Numbers for each healthcare professional group are relatively low, precluding anything other than exploratory analysis. Another limitation was that some doctors appeared to interpret supporting patients in self administration of medicines as personally setting up patients for self administration rather than being generally in support of the principle. This may have made their support appear lower than it was. None of the doctors interpreted the questionnaire in that way during our piloting so this issue was not identified at that stage.

Implications for practice

The gap between patients' preferred and experienced involvement with inpatient medication needs to be addressed. Clinical pharmacists are medication experts with direct contact with patients and thus potentially have an important role to play in closing the gap. A high proportion of healthcare professionals state that they would support patients in being involved with their medication while in hospital, but they need to find ways to encourage this in practice. Davis et al. [12] have shown that patients are more likely to participate in safety behaviours if encouraged to do so by healthcare professionals. More research is needed to understand the barriers to involving patients with their medication while in hospital and interventions should be developed to facilitate involvement. As a follow up to this study, we are planning to conduct an in depth qualitative study to address these issues.

\section{Conclusion}

The majority of patients and healthcare professionals were supportive of hospital inpatients being involved with their medication. However there was a significant gap between this desire for patient involvement and what was reported to be experienced by patients in practice. Female patients and those under 65 wanted a significantly higher level of involvement with their medication than males and those over 65 . This finding needs to be taken into consideration when developing interventions. Few associations were found between healthcare professional support for involvement and their profession and gender. However, pharmacists and nurses were significantly more likely to support patients asking questions about their medicines and self administering their own medicines than doctors.
Funding This study had no specific source of funding. However, some of the data analysis and paper writing was supported by funding from the Health Foundation. The Centre for Medication Safety and Service Quality is affiliated with the Centre for Patient Safety and Service Quality (CPSSQ) at Imperial College Healthcare NHS Trust which is funded by the National Institute of Health Research (NIHR) as a Patient Safety Translational Research Centre.

Conflicts of interest None. The views expressed are those of the author(s) and not necessarily those of the NHS, the NIHR or the Department of Health.

Open Access This article is distributed under the terms of the Creative Commons Attribution License which permits any use, distribution, and reproduction in any medium, provided the original author(s) and the source are credited.

\section{References}

1. Department of Health. An organisation with a memory. Report of an expert group on learning from adverse events in the NHS. London: The Stationery Office; 2000.

2. Department of Health. Building a safer NHS for patients: improving medication safety. A report by the Chief Pharmaceutical Officer. London: The Stationery Office; 2004.

3. Institute of Medicine. To err is human: building a safer health system. Report of the Committee on Quality of Healthcare in America Washington: National Academy Press; 2000.

4. World Health Organization. Quality of care: patient safety. Report by the Secretariat Geneva: World Health Organization; 2002.

5. Department of Health. Pharmacy in England. Building on strengths-delivering the future London: The Stationary Office; 2008.

6. Franklin BD, Reynolds M, Shebl NA, Burnett S, Jacklin A. Prescribing errors in hospital inpatients: a three-centre study of their prevalence, types and causes. Postgrad Med J. 2011;87:739-45.

7. McLeod MC, Barber N, Franklin BD. Methodological variations and their effects on reported medication administration error rates. BMJ Qual Saf. 2013;22:278-89.

8. Cousins DH, Gerrett D, Warner B. A review of medication incidents reported to the National Reporting and Learning System in England and Wales over 6 years (2005-2010). London: National Patient Safety Agency; 2011.

9. Vincent C, Barber N, Franklin BD, Burnett S. The contribution of pharmacy to making Britain a safer place to take medicines. London: Royal Pharmaceutical Society of Great Britain; 2009.

10. Schwappach D, Wernli M. Predictors of chemotherapy patients' intentions to engage in medical error prevention. Oncologist. 2010;15:903-12.

11. McLeod MC. Medication administration processes and systems-exploring the effects of systems-based variation on the safety of medication administration in the UK National Health Service. PHD thesis March 2013, UCL School of Pharmacy.

12. Davis R, Sevdalis N, Vincent C. Patient involvement in patient safety: how willing are patients to participate. BMJ Qual Saf. 2011;20:108-14.

13. Entwistle VA, McCaughan D, Watt IS, Birks Y, Hall J, Peat M, Williams B, Wright J. Speaking up about safety concerns: multi 
setting qualitative study of patients' views and experiences. BMJ Qual Saf. 2010;19:e33.

14. Schwappach DLB, Wernli M. Barriers and facilitators to chemotherapy patients' engagement in medical error prevention. Ann Oncol. 2011;22:424-30.

15. Weingart S, Toth M, Eneman J, Aronson MD, Sands DZ, Ship AN, Davis RB, Phillips RS. Lessons from a patient partnership intervention to prevent adverse drug events. Int J Qual Health Care. 2004;16:449-507.

16. Hall J, Peat M, Birks Y, Golder S, on behalf of the PIPS Group, Entwistle V, Gilbody S, Mansell P, McCaughan D, Sheldon T, Watt I, Williams B, Wright J. Effectiveness of interventions designed to promote patient involvement to enhance safety: a systematic review. Qual Saf Health Care. 2010;1136:1-7.

17. Davis R, Sevdalis N, Vincent C. Patient involvement in patient safety: the Health-Care Professional's perspective. J Patient Saf. 2012;8:182-7.

18. Robson C. Real World Research 3rd rev. ed. Chichester: Wiley; 2011. Chapter 10 Surveys and Questionnaires 237-77.

19. Pedersen JS, Newbould J, Nolte E, The puzzle of changing relationships. Does changing relationships between healthcare service users and providers improve the quality of care? Evidence review. London: The Health Foundation; 2013.
20. Cumbler E, Wald H, Kutner J. Lack of patient knowledge regarding hospital medications. A cross sectional survey. J Hosp Med. 2010;5:83-6.

21. Doherty C, Stavropoulou C. Patients"' willingness and ability to participate in the reduction of clinical errors: a systematic literature review. Soc Sci Med. 2012;75:257-63.

22. Degner LF, Sloan JA. Decision-making during serious illness: what role do patients really want to play? J Clin Epidemiol. 1992;45:941-50.

23. Garfield S, Smith F, Francis SA, Chalmers C. Can patients' preferences for involvement in decision-making regarding the use of medicines be predicted? Patient Educ Couns. 2007;66:361-7.

24. Waterman Ad, Gallagher TH, Garbutt J, Waterman BM, Fraser F, Burroughs TE. Hospitalized patients 'attitudes about and participation in error prevention. J Gen Intern Med. 2006;21:367-70.

25. Say R, Murtagh M, Thomson R. Patients' preference for involvement in medical decision making: a narrative review. Patient Educ Couns. 2006;60:102-14.

26. Deeks PA, Byatt K. Are patients who self-administer their medicines in hospital more satisfied with their care? J Adv Nurs. 2000;31:395-400. 